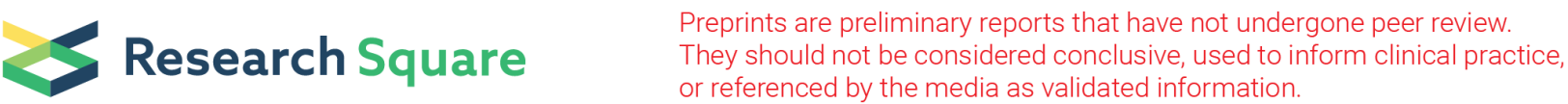

\section{Factors associated with inappropriate overdose response among people who use prescription opioids non-medically in rural Appalachia: A cross- sectional study}

\author{
Alexandria Macmadu \\ Brown University \\ Kelly K. Gurka ( $\square$ kgurka@ufl.edu ) \\ University of Florida https://orcid.org/0000-0003-2779-3234 \\ Herbert I. Linn \\ West Virginia University \\ Gordon S. Smith \\ West Virginia University
}

Research

Keywords: opioids, overdose prevention, rural, Appalachia

Posted Date: July 8th, 2021

DOI: https://doi.org/10.21203/rs.3.rs-676671/v1

License: (c) (i) This work is licensed under a Creative Commons Attribution 4.0 International License.

Read Full License 


\section{Abstract \\ Background}

Opioid-related overdose deaths have accelerated in recent years. In response, overdose education and naloxone distribution (OEND) programs have been implemented across the United States, although many rural Appalachians continue to lack access. Despite the growing number of OEND programs, risk factors for inappropriate overdose response among persons who are training-naïve are currently unknown.

\section{Methods}

We used respondent-driven sampling to recruit and enroll 169 adults who use prescription opioids nonmedically from three rural counties in West Virginia. Participants were interviewed to ascertain experience with witnessed overdose (lifetime and prior-year), characteristics of the most recent witnessed overdose, responses to the witnessed overdose, and OEND acceptability. Logistic regression was used to assess factors associated with inappropriate response to opioid-related overdose.

\section{Results}

Among the 73 ( $43 \%$ of the total sample) participants who witnessed an opioid-related overdose, the majority $(n=53,73 \%)$ reported any inappropriate response. Participants were significantly more likely to report an inappropriate overdose response when the overdose victim was unresponsive $(O R=3.36 ; 95 \%$ $\mathrm{Cl}=1.07,10.58)$. The most common appropriate responses were staying with the victim until recovery or help arrived $(n=66,90 \%)$ and calling $911(n=63,86 \%)$, while the most common inappropriate responses were hitting or slapping the victim $(n=37,51 \%)$ and rubbing the victim with ice or placing them in a cold shower or bath $(n=14,19 \%)$. While most $(n=60,82 \%)$ had never heard of overdose prevention training, the vast majority $(n=69,95 \%)$ were willing to participate in training, particularly those who had responded inappropriately $(n=52,98 \%)$.

\section{Conclusions}

These findings underscore the urgent need for expanded access to OEND programs in at-risk rural communities that lacked coverage. Indeed, information generated by this study informed the development of a statewide naloxone distribution program in WV. These findings also indicate OEND programs are highly acceptable to training-naïve people who use opioids in rural Appalachia. Additional approaches to expand access to harm reduction services in the region, including mobile services and mail-based naloxone distribution should be aggressively pursued.

\section{Introduction}


The epidemic of opioid-related overdose death continues to persist across the United States (US). In recent years, the overdose epidemic has been further exacerbated by the ongoing COVID-19 pandemic and the continued presence of fentanyl in illicit drug supplies (1), and preliminary data indicate that overdose deaths increased by nearly 30\% nationwide from 2019 to 2020 (2). The opioid epidemic has been particularly acute in rural Appalachia, including West Virginia, where the rate of fatal overdose is predicted to have increased by over 45\% from 2019 to 2020 (2). In 2018, the opioid-involved death rate in West Virginia was 42.4 deaths per 100,000 persons-nearly three times the national average (3), and despite national declines in opioid prescribing, West Virginia maintains the highest rates of opioidinvolved (overall and prescription) deaths in the country (3).

In response to longstanding increases in opioid-related overdose deaths, overdose education and naloxone distribution (OEND) programs have been widely implemented across the US (4-10) and have demonstrated efficacy in increasing the odds of overdose recovery and improved knowledge of overdose recognition and management in non-clinical settings (11). However, despite the critically high need, socalled "harm reduction deserts" (12) continue to span much of rural Appalachia. For example, four counties in the southwestern-most region of West Virginia-which were ranked among the most vulnerable to drug overdose mortality in the state (13)-are serviced by a single OEND program operated by a health department (14). As a result, many people who use opioids in rural Appalachia continue to lack accessible OEND programs.

Despite the growing number of OEND programs nationwide, scarce literature has robustly characterized responses to opioid-related overdose among persons who are training-naïve $(6,15)$, and to the authors' knowledge, no prior research has documented the factors associated with inappropriate or less effective responses to opioid-related overdoses. Identifying individuals at greatest risk of responding inappropriately (i.e., those who may benefit most from OEND programs) and characterizing current response practices among the training naive may facilitate improved resource allocation. State health agencies and harm reductionists can then better tailor harm reduction services for persons likely to respond to overdoses in a high-risk sub-region of the country. As part of a program to plan for expansion of harm reduction programs, we sought to assess the acceptability of opioid overdose prevention programs with take-home naloxone among communities in southern WV. This analysis sought to identify respondent characteristics and overdose characteristics associated with inappropriate responses to opioid-related overdose and to characterize training-naïve responses to opioid-related overdose in Appalachia. A secondary aim of this analysis was to assess willingness to participate in an overdose prevention training.

\section{Methods}

\section{Study design and sample}

The present study is part of a larger feasibility study that aimed to assess the acceptability of OEND programs in rural Appalachia. From August 2014 to March 2015, participants were recruited from three 
neighboring counties in southern West Virginia. These counties were selected as sites for recruitment based on their elevated rates of unintentional drug overdose fatality and the availability of community partners for collaboration. Eligibility criteria included being at least 18 years of age, currently residing in one of the three target counties in southern West Virginia, and reporting non-medical use of prescription opioids at least five times in the previous 90 days. Participants who consented to participate in the study were compensated with one $\$ 25$ gift card for their time and one $\$ 10$ gas card for transportation. This study was approved by the Institutional Review Board at West Virginia University.

We consented and enrolled 169 participants who met the eligibility criteria for the pilot study. Among those, 73 (43\%) reported that the most recent overdose they witnessed involved prescription and/or illicit opioids. Individuals indicating that the most recent overdose that they observed did not involve opioids $(96,57 \%)$ were excluded from the present analyses, as the aims of the current study are specific to witnesses to opioid-related overdoses.

\section{Recruitment}

Respondent-driven sampling (RDS) was used to recruit participants. RDS is an effective sampling technique that is commonly used to access hidden populations (16-19). RDS has been successfully implemented to recruit a sample of participants who use stimulants in rural Ohio (19) and a sample of people who predominantly use prescription opioids non-medically in rural Kentucky (20). For this study, community partners who resided in the target counties were trained to recruit and interview participants.

To recruit the first "wave" of participants, these trained community partners first identified "seeds" through a variety of methods, including convenience sampling of persons enrolled in treatment for substance use disorders and by drawing on personal social networks to identify potential participants.

Once participants were screened, the trained community partners conducted structured, in-person interviews in private and semi-private natural settings, including private offices and participants' homes. At the completion of the interview, each participant was provided two referral coupons to distribute to eligible peers. For each referral coupon that was redeemed, the referring participant was compensated with one additional \$15 gift card for up to two additional participants recruited. Referred participants who completed the interview were also invited to refer their peers to the study, and so forth, until several recruitment "chains" comprised of multiple waves of recruits were produced.

\section{Measures}

Data were collected through paper and pencil interviewing and were later entered by study personnel into a secure web-based database (Research Electronic Data Capture [REDCap], version 6.0.3, Vanderbilt University). Measures included sociodemographic characteristics, experience with witnessed overdose (lifetime and prior year), personal experience with nonfatal overdose, characteristics of the most recent witnessed overdose, responses to the witnessed overdose, and OEND acceptability.

Sociodemographic characteristics, such as age, gender, and education, were assessed using conventional items. To measure lifetime witnessed overdoses, participants were asked "Have you ever witnessed a 
drug overdose?" Drug overdose was defined through the following structured priming: "When a drug overdose occurs, a person's skin, lips or fingers may turn blue; their breathing slows down and may stop; or they may nod off and cannot be woken up." If an affirmative response to the item was provided, participants were then asked the number of overdoses ever witnessed and overdoses witnessed in the past year, the date of the most recently witnessed overdose, where the event occurred, the respondent's relationship to the victim, the number of people present at the overdose event, the observed substances used by the victim prior to overdose, the victim's symptoms (e.g., unresponsiveness), and the respondent and others' response to the overdose (e.g., called 911).

To measure the respondent and others' response to witnessed overdoses, participants were asked "What did you or others do to respond to the overdose?" As participants provided responses to this open-ended question, the trained interviewer selected from a pre-determined list of responses on the interview form. If none of the pre-determined potential responses were provided, interviewers would check other and record the response (as close to verbatim as possible). The pre-populated list of potential responses on the form included nothing, yelled at them, hit or slapped them, rubbed them with ice or put them in a cold shower, rubbed knuckles on their chest, walked them around, did CPR or rescue breathing, moved them into recovery position lying on their side, injected milk or salt into them, injected cocaine or methamphetamine into them, administered naloxone, called 911 , and other (i.e., text entry field for respondent-generated other responses). Response options were informed by prior literature (21). Participants were also asked "Did you or anyone stay with the person until he or she recovered or professional help arrived?" Responses to these two questions, as well as respondent-generated other responses, were then categorized as appropriate or inappropriate based on previous studies that assessed OEND efficacy (2126) and current overdose response strategies endorsed by the National Harm Reduction Coalition (27). Participant responses were then categorized as "all appropriate responses" (i.e., only appropriate responses) and "any inappropriate response" (i.e., at least one inappropriate response); similar characterizations have been applied in previous studies (28).

To assess acceptability of OEND programs, participants were asked at the end of the interview whether they had ever heard of an overdose prevention training program, whether they had ever been trained in an overdose prevention program, and whether they would be willing to participate in this type of program. Overdose prevention programs were defined through the following structured priming: "Opioid overdose prevention programs exist in other areas such as big cities like New York and Chicago and other states such as New Mexico. These programs require a 20-40 minute training session that teaches participants about how to prevent an overdose, how to recognize an overdose, best actions to take when someone is overdosing, calling 911 , how to perform rescue breathing, the rescue medication naloxone, and practice using naloxone. Because opioid overdose can be life-threatening, anyone who uses opioids (with or without a prescription) or anyone who comes in contact with people who use opioids (like friends or family members) can benefit from overdose prevention training."

\section{Statistical analyses}


Descriptive statistics were calculated for all characteristics of interest, overall and by "all appropriate responses" and "any inappropriate response". Logistic regression was used to assess characteristics associated with any inappropriate response. Descriptive statistics were also calculated for responses to opioid-related overdoses, stratified by victim responsiveness. In additional exploratory analyses, chisquare tests were used to assess associations between overdose responses and victim responsiveness. All statistical analyses were conducted using SAS, version 9.4.

\section{Results}

Among the 73 participants who witnessed a prescription and/or illicit opioid-related overdose, $20(27 \%)$ reported that the most recent overdose occurred in the past year. The majority $(n=53,73 \%)$ reported at least one inappropriate response, while the remainder $(n=20,27 \%)$ reported only appropriate responses (Table 1). The majority of participants were male $(n=40,55 \%)$, non-Hispanic white $(n=67,92 \%)$, and $30-$ 39 years of age $(n=33,45 \%)$. About a third of participants witnessed an opioid-related overdose in the prior year $(n=23,32 \%)$, and another third $(n=23,32 \%)$ had ever personally experienced a nonfatal overdose. Most opioid-related overdoses occurred in either the victim's home ( $n=41,56 \%)$ or another home $(n=25,34 \%)$, and the overdose victim was most frequently a friend $(n=37,51 \%)$ or a relative $(n=$ $16,22 \%)$ of the respondent. While most participants $(n=60,82 \%)$ had never heard of an overdose prevention training program prior to the survey, the vast majority were willing to participate in an overdose prevention training program $(n=69,95 \%)$. Only one respondent had previously participated in an overdose prevention training program, and this training was completed as part of the respondent's professional duties in the medical field.

Male participants were significantly less likely to report any inappropriate responses than females (unadjusted odds ratio $(\mathrm{OR})=0.30 ; 95 \%$ confidence interval $(\mathrm{Cl})=0.10,0.94)$, and participants were significantly more likely to report any inappropriate response when the victim was unresponsive $(\mathrm{OR}=$ $3.36 ; 95 \% \mathrm{Cl}=1.07,10.58 ; p=0.04)$.

The most commonly reported appropriate responses to an opioid-related overdose were staying with the victim until recovery or help arrived $(n=66,90 \%)$, calling $911(n=63,86 \%)$, and yelling at the victim $(n=$ $39,53 \%$ ) (Table 2). The most commonly reported inappropriate responses were hitting or slapping the victim $(n=37,51 \%)$, rubbing the victim with ice or placing them in a cold shower or bath $(n=14,19 \%)$, and splashing or pouring cold water on the victim $(n=7,10 \%)$. Only one participant reported administering naloxone, and it occurred as part of the participant's professional duties in the medical field. In addition to responses that matched our pre-determined list of potential responses, the most common respondent-generated responses were splashing or pouring water on the victim $(n=7,10 \%)$ and applying a cold cloth to the victim's face or body $(n=5,7 \%)$. Witnesses were significantly more likely to yell at the victim $(p=0.01)$ and hit or slap the victim $(p<0.01)$ when the victim was unresponsive.

\section{Discussion}


In a sample of people who use prescription opioids non-medically in rural Appalachia, we found that the majority reported at least one inappropriate response to the most recent opioid-related overdose that they witnessed, though most reported engaging in appropriate responses as well. The most common appropriate responses were staying with the victim until recovery or help arrived and calling 911, while the most common inappropriate responses were hitting or slapping the victim and rubbing the victim with ice or placing them in a cold shower or bath. Participants were significantly more likely to report an inappropriate overdose response when the overdose victim was unresponsive. The most common respondent-generated responses were splashing or pouring water on the victim (10\%) and applying a cold cloth to the victims face or neck (7\%). While most (82\%) had never heard of overdose prevention training, the vast majority $(95 \%)$ were willing to participate in training. These findings informed the development of a statewide overdose education and naloxone distribution training program. To the authors' knowledge, this study is among the first to identify factors associated with inappropriate overdose response and to characterize training-naïve overdose responses among people who use opioids in rural Appalachia.

\section{Factors associated with inappropriate overdose response}

We found that witnesses were more likely to respond inappropriately when the victim was unresponsive. We hypothesized that individuals who are training-naïve may be more willing to take more extreme measures to revive the victim (i.e., hitting or slapping the victim) when the victim is unresponsive than when the victim is perceived to be semi-responsive or alert. During exploratory analyses, we confirmed that witnesses were significantly more likely to hit or slap the victim when the victim was unresponsive. Considering these findings, OEND programs in rural Appalachia, as in other areas of the country, should strongly discourage hitting/slapping the overdose victim and rubbing the victim with ice or placing them in a cold shower or bath. Additionally, OEND programs in Appalachia specifically should consider emphasizing the ineffectiveness of applying a cold cloth to the victim, as this response appears to be unique to rural Appalachia $(6,15)(21)$.

The present finding that responses to opioid-related overdoses are largely invariable across respondent characteristics and overdose characteristics is notable. We hypothesized that individuals with greater experience with witnessed overdoses (i.e., lifetime witnessed overdoses), those who experienced a previous nonfatal overdose, location of the overdose, relationship to the victim, and number of people present may be associated with increased appropriate response. However, given that the participants in this study were almost exclusively training-naïve, it appears that even when personal motivation is high (e.g., the overdose of a loved one), effectiveness of response remains low. Our findings underscore the urgent need for expanded access to OEND programs in rural Appalachia, and our findings strongly suggest that, even when inappropriate, any actions taken in response to an overdose are good-faith attempts to revive the victim, though some responses may increase the risk of injury to the witness and/or person overdosing.

\section{Training-naïve responses to opioid-related overdose in rural Appalachia}


Based on this study, people who use opioids in rural Appalachia may be more likely to call 911 than their urban counterparts described in previous studies, especially given that at the time of the interviews, the Good Samaritan overdose law had not yet been passed in West Virginia $(6,29,30)$. Two potential explanations for this finding are described. First, the overwhelming majority of reported overdoses in this study occurred in a private setting (e.g., someone's home); whereas, in urban settings, overdose events occur more frequently in public settings $(21,31)$. In public settings, witnesses may perceive abandoning the victim to be lower-risk (i.e., legal risk) and easier (i.e., "bystander effect") (32) than calling 911; whereas in private settings, calling 911 to rescue the victim may be perceived as lower legal risk compared to other options. Second, the tight kinship networks and wide social networks that are characteristic of rural Appalachia may contribute to an overall heightened sense of responsibility for one another, increasing individuals' propensity to call 911 (33). In the present study, the majority of people experiencing overdose were a significant other, relative, or friend of the witness (85\%); correspondingly, greater emotional attachment to the victim may also increase witnesses' likelihood to call 911 . The role of emotional attachment in propensity to call 911 could be examined more deeply in future research.

\section{Willingness to participate in an overdose prevention training}

We found that while most participants had never heard of overdose prevention training, the vast majority of individuals who had witnessed an opioid-related overdose were willing to participate in training. Critically, we found that nearly all participants (98\%) who reported inappropriate responses to opioidrelated overdoses were willing to participate in training. These findings indicate that OEND programs would be highly acceptable to individuals who have witnessed opioid-related overdoses and would benefit from training. Moreover, given that the majority of participants reported any inappropriate overdoses responses, our findings reinforce that expanded access to OEND programs was urgently needed in rural Appalachia. These findings informed program planning and motivated, in part, rapid expansion of naloxone training and distribution in West Virginia. Though extensive, these efforts were not sufficient as OEND remains inaccessible to many in the Appalachian region. State agencies and harm reductionists should partner with county health departments and community-based organizations in those regions of rural Appalachia that are highly vulnerable (13) to overdose mortality and currently lack access (14) to OEND programs and other harm reduction services. Mobile harm reduction and treatment services $(34,35)$ may be particularly effective in reaching small, at-risk communities where brick and mortar programs may not be feasible. Finally, to enhance access to harm reduction services in rural Appalachia, state officials must reverse regulations that currently prohibit pharmacy-based naloxone distribution by mail (36). Mail-based naloxone distribution and harm reduction programs at the state-level $(37,38)$ should be aggressively pursued and promoted in at-risk rural communities as well.

\section{Limitations}

These findings should be considered in light of several limitations. First, details regarding witnessed overdose events may have been subject to errors in recall (e.g., fusing of events or repression of events) because witnessing an overdose can be traumatic (39); additionally, in some cases, the most recently witnessed overdose occurred several years prior to the study interview, which can affect recall. Second, 
non-random sampling could produce underrepresentation of certain subgroups within the population; for example, because RDS was used to sample participants, individuals who belong to small social networks were less likely to be recruited to participate. Finally, the present study assesses characteristics of witnessed overdose from the witnesses' perspective (e.g., relationship to the victim); however, the overdose response item interrogates how either participant or others who were present responded to the overdose. In instances when there are multiple bystanders, this mismatch of individual characteristics and overdose response may fail to capture key associations that were assessed in this study. Nonetheless, studies on the effects of egocentric bias suggest that participants are more likely to recall and report their own actions rather than the actions of others $(40,41)$. To reduce potential error, future studies should separate overdose response of participants and others into two distinct categories.

\section{Conclusions}

In this cross-sectional study of people who use prescription opioids non-medically in rural Appalachia, we found that the majority of participants responded with at least one inappropriate response at the most recently witnessed opioid-related overdose. However, most also engaged in recommended responses, such as staying with the victim until help arrived and calling 911 . Witnesses were more likely to respond inappropriately when the overdose victim was unresponsive. We characterized the most common appropriate and inappropriate responses that were reported by witnesses, as well as the most common respondent-generated responses. While most had never heard of overdose prevention training, the majority were willing to participate in training-particularly those who had responded inappropriately. Our findings indicate that OEND programs are highly acceptable to training-naïve people who use opioids in rural Appalachia, and our results underscore the continued urgent need for expanded access to OEND programs in at-risk rural communities that currently lack coverage.

\section{Declarations}

\section{Ethics approval}

The Institutional Review Board at West Virginia University approved this study. An ethics approval statement is included in the Methods section.

\section{Consent for publication}

Not applicable.

\section{Availability of data and materials}

The data collection instruments and datasets used and/or analyzed during the current study are available from the corresponding author on reasonable request.

\section{Competing interests}


The authors declare that they have no competing interests.

\section{Funding}

This pilot study was supported by a grant from the National Institute of General Medical Sciences of the National Institutes of Health (5U54GM104942-05), and AM was supported by a grant from the National Institute on Drug Abuse (F31-DA052971-01). The content is solely the responsibility of the authors and does not necessarily represent the official views of the National Institutes of Health. The sponsors had no role in the study design; the collection, analysis and interpretation of data; the writing of the report; or in the decision to submit the article for publication.

\section{Authors' contributions}

$\mathrm{KKG}, \mathrm{HL}$, and $\mathrm{AM}$ made significant contributions to the study design and conduct, and KKG secured funding. KKG and AM developed the research question and drafted the analysis plan. AM conducted the analyses and led the writing. All authors contributed to the interpretation of the data, and KKG, $\mathrm{HL}$, and GS critically revised the manuscript. All authors approved the final manuscript for publication.

\section{Acknowledgements}

The authors would like to thank the participants in this study for sharing their time and experiences with us, as well as our project interviewers, researchers, and staff. We would also like to give special thanks to Brandon Rhodes for his tireless assistance in participant recruitment.

\section{Authors' information}

KKG was on faculty at West Virginia University when the study was conducted. The West Virginia Bureau for Public Health (BPH) currently employs her as a consultant for evaluation of the Centers' for Disease Control-funded Overdose Data to Action award to $\mathrm{BPH}$.

\section{References}

1. American Medical Association. Issue brief: Drug overdose epidemic worsened during COVID pandemic 2021 [Available from: https://www.ama-assn.org/system/files/2020-12/issue-briefincreases-in-opioid-related-overdose.pdf.

2. Ahmad F, Rossen L, Sutton P. Provisional drug overdose death counts National Center for Health Statistics 2021 [Available from: https://www.cdc.gov/nchs/nvss/vsrr/drug-overdose-data.htm.

3. Wilson N, Kariisa M, Seth P, Smith IVH, Davis NL. Drug and opioid-involved overdose deaths-United States, 2017-2018. Morb Mortal Wkly Rep. 2020;69(11):290-7.

4. Siegler A, Huxley-Reicher Z, Maldjian L, Jordan R, Oliver C, Jakubowski A, et al. Naloxone use among overdose prevention trainees in New York City: A longitudinal cohort study. Drug and Alcohol Dependence. 2017. 
5. Rowe C, Santos GM, Vittinghoff E, Wheeler E, Davidson P, Coffin PO. Predictors of participant engagement and naloxone utilization in a community-based naloxone distribution program. Addiction. 2015;110(8):1301-10.

6. Doe-Simkins M, Quinn E, Xuan Z, Sorensen-Alawad A, Hackman H, Ozonoff A, et al. Overdose rescues by trained and untrained participants and change in opioid use among substance-using participants in overdose education and naloxone distribution programs: a retrospective cohort study. BMC Public Health. 2014;14(1):297.

7. Wheeler E, Davidson PJ, Jones TS, Irwin KS. Community-based opioid overdose prevention programs providing naloxone-United States, 2010. MMWR. 2012;61(6):101.

8. Yokell MA, Green TC, Bowman S, McKenzie M, Rich JD. Opioid overdose prevention and naloxone distribution in Rhode Island. Medicine Health Rhode Island. 2011;94(8):240.

9. Albert S, Brason I, Fred W, Sanford CK, Dasgupta N, Graham J, et al. Project Lazarus: Communitybased overdose prevention in rural North Carolina. Pain Med. 2011;12:s2.

10. Clark AK, Wilder CM, Winstanley EL. A systematic review of community opioid overdose prevention and naloxone distribution programs. J Addict Med. 2014;8(3):153-63.

11. Giglio RE, Li G, DiMaggio CJ. Effectiveness of bystander naloxone administration and overdose education programs: a meta-analysis. InjuryEpidemiology. 2015;2(1):1-9.

12. Johnson D. Harm Reduction Deserts: When Services Are Miles or Hours Away. Filter Magazine 2021 [Available from: https://filtermag.org/harm-reduction-deserts/.

13. West Virginia Department of Health \& Human Resources. County-level Vulnerability to Overdose Deaths in West Virginia 2020 [Available from:

https://oeps.wv.gov/HCV/documents/data/WV_OD_Vulnerability_Assessment.pdf.

14. NEXT Distro. Harm Reduction in West Virginia-Map 2021 [Available from: https://nextdistro.org/westvirginia.

15. Green TC, Heimer R, Grau LE. Distinguishing signs of opioid overdose and indication for naloxone: an evaluation of six overdose training and naloxone distribution programs in the United States. Addiction. 2008;103(6):979-89.

16. Heckathorn DD. Respondent-driven sampling: a new approach to the study of hidden populations. Soc Probl. 1997;44(2):174-99.

17. Heckathorn DD. Respondent-driven sampling II: deriving valid population estimates from chainreferral samples of hidden populations. Soc Probl. 2002;49(1):11-34.

18. Wang J, Carlson RG, Falck RS, Siegal HA, Rahman A, Li L. Respondent-driven sampling to recruit MDMA users: a methodological assessment. Drug Alcohol Depend. 2005;78(2):147-57.

19. Wang J, Falck RS, Li L, Rahman A, Carlson RG. Respondent-driven sampling in the recruitment of illicit stimulant drug users in a rural setting: findings and technical issues. J Behav Addict Addictive behaviors. 2007;32(5):924-37. 
20. Havens JR, Oser CB, Knudsen HK, Lofwall M, Stoops WW, Walsh SL, et al. Individual and network factors associated with non-fatal overdose among rural Appalachian drug users. Drug Alcohol Depend. 2011;115(1):107-12.

21. Lankenau SE, Wagner KD, Silva K, Kecojevic A, Iverson E, McNeely M, et al. Injection drug users trained by overdose prevention programs: responses to witnessed overdoses. JCommunity Health. 2013;38(1):133-41.

22. Bennett AS, Bell A, Tomedi L, Hulsey EG, Kral AH. Characteristics of an overdose prevention, response, and naloxone distribution program in Pittsburgh and Allegheny County, Pennsylvania. J Urban Health. 2011;88(6):1020-30.

23. Enteen L, Bauer J, McLean R, Wheeler E, Huriaux E, Kral AH, et al. Overdose prevention and naloxone prescription for opioid users in San Francisco. JUrban Health. 2010;87(6):931-41.

24. Piper TM, Stancliff S, Rudenstine S, Sherman S, Nandi V, Clear A, et al. Evaluation of a naloxone distribution and administration program in New York City. Subst Use Misuse. 2008;43(7):858-70.

25. Tobin KE, Sherman SG, Beilenson P, Welsh C, Latkin CA. Evaluation of the Staying Alive programme: training injection drug users to properly administer naloxone and save lives. Int J Drug Policy. 2009;20(2):131-6.

26. Wagner KD, Valente TW, Casanova M, Partovi SM, Mendenhall BM, Hundley JH, et al. Evaluation of an overdose prevention and response training programme for injection drug users in the Skid Row area of Los Angeles, CA. Int J Drug Policy. 2010;21(3):186-93.

27. National Harm Reduction Coalition. Training Guide: Opioid Overdose Basics 2021 [Available from: https://harmreduction.org/issues/overdose-prevention/overview/overdose-basics/responding-toopioid-overdose/.

28. Kinnard EN, Howe CJ, Kerr T, Hass VS, Marshall BD. Self-reported changes in drug use behaviors and syringe disposal methods following the opening of a supervised injecting facility in Copenhagen, Denmark. Harm Reduct J. 2014;11(1):29.

29. Seal KH, Downing M, Kral AH, Singleton-Banks S, Hammond J-P, Lorvick J, et al. Attitudes about prescribing take-home naloxone to injection drug users for the management of heroin overdose: a survey of street-recruited injectors in the San Francisco Bay Area. J Urban Health. 2003;80(2):291301.

30. Tobin KE, Davey MA, Latkin CA. Calling emergency medical services during drug overdose: an examination of individual, social and setting correlates. Addiction. 2005;100(3):397-404.

31. Kelly A-M, Kerr D, Koutsogiannis Z, Dietze P, Patrick I, Walker T. Randomised trial of intranasal versus intramuscular naloxone in prehospital treatment for suspected opioid overdose. Med J Aust. 2005;182(1):24-7.

32. Hudson JM, Bruckman AS. The bystander effect: A lens for understanding patterns of participation. Journal Learning Sciences. 2004;13(2):165-95.

33. Keyes KM, Cerdá M, Brady JE, Havens JR, Galea S. Understanding the rural-urban differences in nonmedical prescription opioid use and abuse in the United States. Am J Public Health. 
2014;104(2):e52-e9.

34. Janssen PA, Gibson K, Bowen R, Spittal PM, Petersen KL. Peer support using a mobile access van promotes safety and harm reduction strategies among sex trade workers in Vancouver's Downtown Eastside. J Urban Health. 2009;86(5):804-9.

35. Regis C, Gaeta JM, Mackin S, Baggett TP, Quinlan J, Taveras EM. Community Care in Reach: Mobilizing Harm Reduction and Addiction Treatment Services for Vulnerable Populations. Frontiers in Public Health. 2020;8:501.

36. CVS Pharmacy. Naloxone 2021 [Available from: https://www.cvs.com/content/prescription-drugabuse/save-a-life.

37. Yang C, Favaro J, Meacham MC. NEXT harm reduction: an online, mail-based naloxone distribution and harm-reduction program. Am J Public Health. 2021;111(4):667-71.

38. Prevent Overdose RI. Get Naloxone 2021 [Available from: https://preventoverdoseri.org/getnaloxone/?src=mnu.

39. Winstanley EL. The bell tolls for thee \& thine: compassion fatigue \& the overdose epidemic. International J Drug Policy. 2020;85:102796.

40. Brawley L. Unintentional egocentric biases in attributions. J Sport Psychology. 1984;6(3):264-78.

41. Ross M, Sicoly F. Egocentric biases in availability and attribution. J Personality Social Psych. 1979;37(3):322.

\section{Tables}


Table 1

Characteristics associated with any inappropriate response to opioid-related overdoses among people who use prescription opioids non-medically in rural Appalachia.

\begin{tabular}{|c|c|c|c|c|}
\hline & $\begin{array}{l}\text { Total } \\
N= \\
73\end{array}$ & $\begin{array}{l}\text { Any inappropriate } \\
\text { response } \\
n=53\end{array}$ & $\begin{array}{l}\text { All appropriate } \\
\text { responses } \\
n=20\end{array}$ & $\begin{array}{l}\text { Unadjusted OR } \\
(95 \% \mathrm{Cl})\end{array}$ \\
\hline \multicolumn{5}{|l|}{$\begin{array}{l}\text { Respondent } \\
\text { characteristics }\end{array}$} \\
\hline \multicolumn{5}{|l|}{ Sex } \\
\hline Male & $\begin{array}{l}40 \\
(55 \%)\end{array}$ & $25(47 \%)$ & $15(75 \%)$ & $0.30(0.10,0.94)$ \\
\hline Female & $\begin{array}{l}33 \\
(45 \%)\end{array}$ & $28(53 \%)$ & $5(25 \%)$ & 1 (ref) \\
\hline \multicolumn{5}{|l|}{ Age } \\
\hline $50+$ & $\begin{array}{l}8 \\
(11 \%)\end{array}$ & $5(9 \%)$ & $3(15 \%)$ & $0.83(0.13,5.40)$ \\
\hline $40-49$ & $\begin{array}{l}20 \\
(27 \%)\end{array}$ & $14(26 \%)$ & $6(30 \%)$ & $1.17(0.25,5.41)$ \\
\hline $30-39$ & $\begin{array}{l}33 \\
(45 \%)\end{array}$ & $7(35 \%)$ & $26(49 \%)$ & $1.86(0.43,8.01)$ \\
\hline $18-29$ & $\begin{array}{l}12 \\
(16 \%)\end{array}$ & $8(15 \%)$ & $4(20 \%)$ & 1 (ref) \\
\hline \multicolumn{5}{|l|}{ Race and ethnicity } \\
\hline Other & $\begin{array}{l}6 \\
(8 \%)\end{array}$ & $4(8 \%)$ & $2(10 \%)$ & $0.74(0.12,4.36)$ \\
\hline White, non-Hispanic & $\begin{array}{l}67 \\
(92 \%)\end{array}$ & $49(92 \%)$ & $18(90 \%)$ & 1 (ref) \\
\hline \multicolumn{5}{|l|}{ Marital Status } \\
\hline Never married & $\begin{array}{l}26 \\
(36 \%)\end{array}$ & $16(30 \%)$ & $10(50 \%)$ & $0.28(0.07,1.05)$ \\
\hline $\begin{array}{l}\text { Separated, divorced, or } \\
\text { widowed }\end{array}$ & $\begin{array}{l}20 \\
(27 \%)\end{array}$ & $14(26 \%)$ & $6(30 \%)$ & $0.41(0.10,1.69)$ \\
\hline Married & $\begin{array}{l}27 \\
(37 \%)\end{array}$ & $23(43 \%)$ & $4(20 \%)$ & 1 (ref) \\
\hline \multicolumn{5}{|l|}{ Employed } \\
\hline Yes & $\begin{array}{l}11 \\
(15 \%)\end{array}$ & $10(19 \%)$ & $1(5 \%)$ & $4.42(0.53,37.01)$ \\
\hline
\end{tabular}




\begin{tabular}{|c|c|c|c|c|}
\hline & $\begin{array}{l}\text { Total } \\
N= \\
73\end{array}$ & $\begin{array}{l}\text { Any inappropriate } \\
\text { response } \\
n=53\end{array}$ & $\begin{array}{l}\text { All appropriate } \\
\text { responses } \\
n=20\end{array}$ & $\begin{array}{l}\text { Unadjusted OR } \\
(95 \% \mathrm{Cl})\end{array}$ \\
\hline No & $\begin{array}{l}62 \\
(85 \%)\end{array}$ & $43(81 \%)$ & $19(95 \%)$ & 1 (ref) \\
\hline \multicolumn{5}{|l|}{ Education } \\
\hline Some college or greater & $\begin{array}{l}10 \\
(14 \%)\end{array}$ & $8(15 \%)$ & $2(10 \%)$ & $1.27(0.22,7.45)$ \\
\hline $\begin{array}{l}\text { High school diploma or } \\
\text { GED }\end{array}$ & $\begin{array}{l}34 \\
(47 \%)\end{array}$ & $23(43 \%)$ & $11(55 \%)$ & $0.67(0.22,2.03)$ \\
\hline Less than high school & $\begin{array}{l}29 \\
(40 \%)\end{array}$ & $22(42 \%)$ & $7(35 \%)$ & 1 (ref) \\
\hline \multicolumn{5}{|l|}{$\begin{array}{l}\text { Lifetime witnessed } \\
\text { overdoses }^{\text {a }}\end{array}$} \\
\hline 3 or greater & $\begin{array}{l}29 \\
(40 \%)\end{array}$ & $23(43 \%)$ & $6(30 \%)$ & $1.49(0.43,5.22)$ \\
\hline 2 & $\begin{array}{l}18 \\
(25 \%)\end{array}$ & $11(21 \%)$ & $7(35 \%)$ & $0.61(0.17,2.22)$ \\
\hline 1 & $\begin{array}{l}25 \\
(35 \%)\end{array}$ & $18(34 \%)$ & $7(35 \%)$ & 1 (ref) \\
\hline \multicolumn{5}{|l|}{$\begin{array}{l}\text { Witnessed overdose in } \\
\text { prior year }\end{array}$} \\
\hline Yes & $\begin{array}{l}23 \\
(32 \%)\end{array}$ & $18(34 \%)$ & $5(25 \%)$ & $1.54(0.48,4.93)$ \\
\hline No & $\begin{array}{l}50 \\
(68 \%)\end{array}$ & $35(66 \%)$ & $15(75 \%)$ & 1 (ref) \\
\hline \multicolumn{5}{|l|}{$\begin{array}{l}\text { Ever nonfatally } \\
\text { overdosed }\end{array}$} \\
\hline Yes & $\begin{array}{l}23 \\
(32 \%)\end{array}$ & $19(36 \%)$ & $4(20 \%)$ & $2.24(0.65,7.66)$ \\
\hline No & $\begin{array}{l}50 \\
(68 \%)\end{array}$ & $34(64 \%)$ & $16(80 \%)$ & 1 (ref) \\
\hline \multicolumn{5}{|l|}{$\begin{array}{l}\text { Overdose } \\
\text { characteristics }\end{array}$} \\
\hline \multicolumn{5}{|l|}{ Location } \\
\hline Another home & $\begin{array}{l}25 \\
(34 \%)\end{array}$ & $18(34 \%)$ & 7 (35\%) & $0.94(0.31,2.87)$ \\
\hline
\end{tabular}




\begin{tabular}{|c|c|c|c|c|}
\hline & $\begin{array}{l}\text { Total } \\
N= \\
73\end{array}$ & $\begin{array}{l}\text { Any inappropriate } \\
\text { response } \\
n=53\end{array}$ & $\begin{array}{l}\text { All appropriate } \\
\text { responses } \\
n=20\end{array}$ & $\begin{array}{l}\text { Unadjusted OR } \\
(95 \% \mathrm{Cl})\end{array}$ \\
\hline Somewhere else & $\begin{array}{l}6 \\
(8 \%)\end{array}$ & $4(8 \%)$ & $2(10 \%)$ & $0.73(0.12,4.58)$ \\
\hline Victim's home & $\begin{array}{l}41 \\
(56 \%)\end{array}$ & $30(57 \%)$ & $11(55 \%)$ & 1 (ref) \\
\hline Missing & $\begin{array}{l}1 \\
(1 \%)\end{array}$ & $1(2 \%)$ & $0(0 \%)$ & - \\
\hline \multicolumn{5}{|l|}{$\begin{array}{l}\text { Victim was } \\
\text { unresponsive }\end{array}$} \\
\hline Yes & $\begin{array}{l}33 \\
(45 \%)\end{array}$ & 28 (53\%) & $5(25 \%)$ & $3.36(1.07,10.58)$ \\
\hline No & $\begin{array}{l}40 \\
(55 \%)\end{array}$ & $25(47 \%)$ & $15(75 \%)$ & 1 (ref) \\
\hline \multicolumn{5}{|c|}{ Relationship to victim } \\
\hline Relative & $\begin{array}{l}16 \\
(22 \%)\end{array}$ & $15(28 \%)$ & $1(5 \%)$ & $7.50(0.65,87.19)$ \\
\hline Friend & $\begin{array}{l}37 \\
(51 \%)\end{array}$ & $25(47 \%)$ & $12(60 \%)$ & $1.04(0.22,4.90)$ \\
\hline Other & $\begin{array}{l}11 \\
(15 \%)\end{array}$ & $7(13 \%)$ & $4(20 \%)$ & $0.88(0.14,5.58)$ \\
\hline Significant other & $\begin{array}{l}9 \\
(12 \%)\end{array}$ & $6(11 \%)$ & $3(15 \%)$ & 1 (ref) \\
\hline \multicolumn{5}{|l|}{$\begin{array}{l}\text { Number of people } \\
\text { present }^{b}\end{array}$} \\
\hline 5 or greater & $\begin{array}{l}31 \\
(42 \%)\end{array}$ & $23(43 \%)$ & $8(40 \%)$ & $0.45(0.11,1.95)$ \\
\hline 4 & $\begin{array}{l}20 \\
(27 \%)\end{array}$ & $11(21 \%)$ & $9(45 \%)$ & $0.19(0.04,0.87)$ \\
\hline 3 or fewer & $\begin{array}{l}22 \\
(30 \%)\end{array}$ & $19(36 \%)$ & $3(15 \%)$ & 1 (ref) \\
\hline \multicolumn{5}{|c|}{$\begin{array}{l}\text { Overdose prevention } \\
\text { training }\end{array}$} \\
\hline \multicolumn{5}{|c|}{ Has heard of training } \\
\hline Yes & $\begin{array}{l}13 \\
(18 \%)\end{array}$ & $11(21 \%)$ & $2(10 \%)$ & $2.36(0.47,11.73)$ \\
\hline
\end{tabular}




\begin{tabular}{|c|c|c|c|c|}
\hline & $\begin{array}{l}\text { Total } \\
N= \\
73\end{array}$ & $\begin{array}{l}\text { Any inappropriate } \\
\text { response } \\
n=53\end{array}$ & $\begin{array}{l}\text { All appropriate } \\
\text { responses } \\
n=20\end{array}$ & $\begin{array}{l}\text { Unadjusted OR } \\
(95 \% \mathrm{Cl})\end{array}$ \\
\hline No & $\begin{array}{l}60 \\
(82 \%)\end{array}$ & $42(79 \%)$ & $18(90 \%)$ & 1 (ref) \\
\hline \multicolumn{5}{|c|}{$\begin{array}{l}\text { Willing to participate in } \\
\text { training }\end{array}$} \\
\hline Yes & $\begin{array}{l}69 \\
(95 \%)\end{array}$ & $52(98 \%)$ & $17(85 \%)$ & $9.17(0.89,94.14)$ \\
\hline No & $\begin{array}{l}4 \\
(5 \%)\end{array}$ & $1(2 \%)$ & $3(15 \%)$ & 1 (ref) \\
\hline \multicolumn{5}{|c|}{$\begin{array}{l}\text { Has participated in } \\
\text { training }^{c}\end{array}$} \\
\hline Yes & $\begin{array}{l}1 \\
(7 \%)\end{array}$ & 0 & 1 & - \\
\hline No & $\begin{array}{l}12 \\
(92 \%)\end{array}$ & 11 & 1 & 1 (ref) \\
\hline \multicolumn{4}{|c|}{ a Categories do not sum to total due to missing data } & \\
\hline
\end{tabular}


Table 2

Appropriate and inappropriate responses to opioid-related overdoses among people who use prescription opioids nonmedically in rural Appalachia, stratified by victim responsivenessa

\begin{tabular}{|c|c|c|c|c|}
\hline & $\begin{array}{l}\text { Total } \\
N=73\end{array}$ & $\begin{array}{l}\text { Responsive } \\
n=40\end{array}$ & $\begin{array}{l}\text { Unresponsive } \\
n=33\end{array}$ & $\begin{array}{l}P \\
\text { value }\end{array}$ \\
\hline \multicolumn{5}{|l|}{ Appropriate } \\
\hline $\begin{array}{l}\text { Someone stayed with them until recovery or help } \\
\text { arrived }\end{array}$ & $\begin{array}{l}66 \\
(90 \%)\end{array}$ & $35(88 \%)$ & $31(94 \%)$ & 0.36 \\
\hline Called 911 & $\begin{array}{l}63 \\
(86 \%)\end{array}$ & $33(83 \%)$ & $30(91 \%)$ & 0.31 \\
\hline Yelled at them & $\begin{array}{l}39 \\
(53 \%)\end{array}$ & $16(40 \%)$ & $23(70 \%)$ & 0.01 \\
\hline Performed CPR or rescue breathing & $\begin{array}{l}27 \\
(37 \%)\end{array}$ & $15(38 \%)$ & $12(36 \%)$ & 0.92 \\
\hline Placed them in recovery position & $6(8 \%)$ & $2(5 \%)$ & $4(12 \%)$ & 0.28 \\
\hline Rubbed knuckles on their chest & $4(5 \%)$ & $1(3 \%)$ & $3(9 \%)$ & 0.25 \\
\hline Shook them ${ }^{b}$ & $4(5 \%)$ & $3(8 \%)$ & $1(3 \%)$ & 0.42 \\
\hline Administered naloxone ${ }^{c}$ & $1(1 \%)$ & $0(0 \%)$ & $1(3 \%)$ & 0.99 \\
\hline Checked vitals ${ }^{\mathrm{b}}$ & $1(1 \%)$ & $1(3 \%)$ & $0(0 \%)$ & 0.99 \\
\hline Took away their drugs ${ }^{b}$ & $1(1 \%)$ & $1(3 \%)$ & $0(0 \%)$ & 0.99 \\
\hline \multicolumn{5}{|l|}{ Inappropriate } \\
\hline Hit or slapped them & $\begin{array}{l}37 \\
(51 \%)\end{array}$ & $13(33 \%)$ & $24(73 \%)$ & $\begin{array}{l}< \\
0.01\end{array}$ \\
\hline Rubbed with ice or placed in cold shower or bath & $\begin{array}{l}14 \\
(19 \%)\end{array}$ & $6(15 \%)$ & $8(24 \%)$ & 0.32 \\
\hline Splashed or poured water on them ${ }^{b}$ & $7(10 \%)$ & $3(8 \%)$ & $4(12 \%)$ & 0.51 \\
\hline Walked them around & $5(7 \%)$ & $3(8 \%)$ & $2(6 \%)$ & 0.81 \\
\hline Applied cold rag/washcloth to face or neck ${ }^{b}$ & $5(7 \%)$ & $3(8 \%)$ & $2(6 \%)$ & 0.81 \\
\hline Nothing & $3(4 \%)$ & $3(8 \%)$ & $0(0 \%)$ & 0.98 \\
\hline Drove them to hospital ${ }^{b}$ & $3(4 \%)$ & $1(3 \%)$ & $2(6 \%)$ & 0.46 \\
\hline Other inappropriate ${ }^{b, d}$ & $2(3 \%)$ & $1(3 \%)$ & $1(3 \%)$ & 0.89 \\
\hline Injected milk or salt into them & $0(0 \%)$ & $0(0 \%)$ & $0(0 \%)$ & - \\
\hline
\end{tabular}




\begin{tabular}{|c|c|c|c|c|}
\hline & $\begin{array}{l}\text { Total } \\
N=73\end{array}$ & $\begin{array}{l}\text { Responsive } \\
n=40\end{array}$ & $\begin{array}{l}\text { Unresponsive } \\
n=33\end{array}$ & $\begin{array}{l}P \\
\text { value }\end{array}$ \\
\hline Injected cocaine or methamphetamine into them & $0(0 \%)$ & $0(0 \%)$ & $0(0 \%)$ & - \\
\hline \multicolumn{4}{|l|}{${ }^{b}$ Respondent generated response. } & \\
\hline${ }^{\mathrm{C}}$ Respondent administered naloxone as part of his or her professional duties in the medical field. & her prof & sional duties & the medical fielc & \\
\hline
\end{tabular}

